\title{
MANAJEMEN STRATEGIK LEMBAGA PENDIDIKAN ISLAM \\ DALAM MENINGKATKAN MUTU PENDIDIKAN \\ Studi Kasus di Madrasah Aliyah Nahdlatul Ulama Gondang Sragen
}

\author{
Etik Kurniawati \\ STIT Madina Sragen \\ etikkurniawati46@gmail.com
}

\begin{abstract}
The quality of education in Islamic educational institutions today is encouraged unmediately by the various strategies and approaches. It is underpinned based on a strong desire to build a more dignified education. A strong desire is unfortunately not based on good management so that some Islamic educational institutions should decline. Eventually some Islamic educational institutions today are often considered as an institution that has not been able to manage and produce out put that satisfy customers. The focus of this research is: (1) How is the formulation strategy Islamic educational institutions in improving the quality of education in $M A N U$ Gondang Sragen? (2) How is the implementation strategy of Islamic educational institutions in improving the quality of education in MA NU Gondang Sragen? (3) How is the evaluation strategy of Islamic educational institutions in improving the quality of education in $M A N U$ Gondang Sragen?. In this study, researchers used a qualitative approach with case study design. The data collection conducted by interview, observation and documentation. Data were analyzed by using data reduction techniques, followed by a presentation of data, and drawing conclusions. Results of this research are: (1) Formulation of strategies in $M A N U$ Gondang Sragen done by first formulating the vision and mission of taking into account the internal and external environment, followed by setting goals and targets and continued by the determining strategies. (2) Implementation of the strategy at MA NU Gondang Sragen done by outlining strategies have been formulated in the form of activities. Technical implementation is submitted to the coordinator of activities in coordination with the principal. System monitoring is done by applying an intensive communication and routine control to the coordinator of activities. (3) Evaluation strategies in $M A N U$ Gondang Sragen done through formal and informal meetings. Formal meetings are routinely performed both at the internal level and overall field. By this meeting, then formulated corrective measures forward.
\end{abstract}

Keywords: Education quality, strategic management, Institute of Islamic Education 


\section{A. PENDAHULUAN}

Pendidikan merupakan salah satu kunci bagi kemajuan bangsa dan negara. Karena pendidikan merupakan proses untuk meningkatkan, memperbaiki, mengubah pengetahuan, keterampilan dan sikap serta tata laku seseorang atau kelompok orang dalam usaha mencerdaskan kehidupan manusia melalui kegiatan bimbingan, pengajaran dan penelitian. Proses pendidikan menunjukkan adanya aktivitas dalam bentuk tindakan aktif melalui suatu interaksi yang dinamis dan dilakukan secara sadar dalam usaha mencapai tujuan yang diinginkan. Oleh karena itu, tindakan pendidikan selalu bersifat aktif dan terencana, maka pendidikan merupakan suatu perbuatan atau tindakan yang dilakukan secara sadar agar terjadi perubahan sikap dan tata laku yang diharapkan yaitu terjadinya pemanusiaan manusia yang cerdas, terampil, mandiri, berdisplin dan berakhlak mulia.

Jika ditelaah lebih jauh, peningkatan kualitas manusia secara menyeluruh sebenarnya telah diajarkan oleh Allah SWT, sebagaimana dalam Al-Quran Surat Al-Alaq ayat 1-5 yang berbunyi:

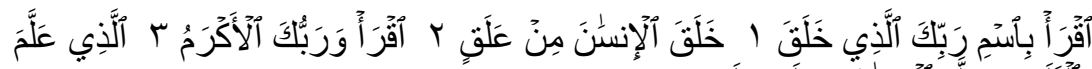

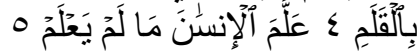

Artinya: "Bacalah dengan (menyebut) nama Tuhanmu yang Menciptakan, Dia telah menciptakan manusia dari segumpal darah, Bacalah, dan Tuhanmulah yang Maha pemurah, Yang 
mengajar (manusia) dengan perantaran kalam, Dia mengajar kepada manusia apa yang tidak diketahuinya". ${ }^{1}$

Dari ayat diatas dapat dipahami bahwa pendidikan mencakup segala aspek jagat raya ini, bukan hanya terbatas pada manusia semata, namun dengan menempatkan Allah sebagai Pendidik Yang Maha Agung. Pengaruh pembawaan dan pengaruh pendidikan diharapkan akan menjadi satu kekuatan yang terpadu yang berproses ke arah pembentukan kepribadian yang sempurna. Oleh karena itu, pendidikan sejatinya tidak hanya menekankan pada pengajaran yang berorientasi pada intelektualitas penalaran semata, melainkan lebih menekankan kepada pendidikan yang mengarah kepada pembentukan keribadian yang utuh dan bulat.

Upaya-upaya peningkatan mutu pendidikan terus dilakukan oleh berbagai pihak dengan berbagai pendekatan. Upaya-upaya tersebut dilandasi suatu kesadaran betapa pentingnya peranan pendidikan dalam pengembangan sumber daya manusia (SDM) dan pengembangan watak bangsa (Nation Character Building) untuk kemajuan masyarakat dan bangsa. Harkat dan martabat suatu bangsa sangat ditentukan oleh kualitas pendidikannya. Dalam konteks bangsa Indonesia, peningkatan mutu pendidikan merupakan sasaran pembangunan di bidang pendidikan nasional dan merupakan bagian integral dari upaya peningkatan kualitas manusia Indonesia secara menyeluruh. $^{2}$

\footnotetext{
${ }^{1}$ Departemen Agama, Al-Qur'an dan Terjemahan, (Kudus, PT. Menara Kudus, 2006 ), hlm.597

${ }^{2}$ E. Mulyasa, Manajemen Berbasis Sekolah, Konsep, Strategi, dan 
Jika dikaitkan dengan pendidikan Islam, Mujamil Qomar menegaskan bahwa misi pendidikan Islam lebih kompleks dari pada pendidikan umum. Paling tidak, ada dua beban misi yang harus dilaksanakan oleh lembaga pendidikan Islam yaitu misi akademik dan misi keagamaan. ${ }^{3}$ Dua misi inilah yang harus diwujudkan oleh setiap lembaga pendidikan Islam jika ingin menjadi lembaga yang unggul.

Dari dua misi diatas, maka salah satu alternatif dalam usaha untuk membentuk kepribadian yang utuh dan bulat yang sesuai dengan harapan Islam adalah dengan didirikannya lembaga-lembaga pendidikan yang berlandaskan Islam. Lembaga Pendidikan Islam adalah suatu bentuk organisasi yamg diadakan untuk mengembangkan lembaga Islam, baik yang permanen maupun yang berabah-ubah dan mempunyai pola tertentu dalam memerankan fungsinya serta mempunyai straktur organisasi yang dapat mengikat individu yang berada dalam naungannya, sehingga lembaga mempunyai kekuatan tersendiri. ${ }^{4}$

Lembaga pendidikan Islam diatas menurut Prim Masrokan, perlu adanya pengelolaan atau penerapan manajerial yang seefektif mungkin. Apabila tidak dilakukan, lembaga pendidikan Islam tidak akan maju dan bersaing secara kompetitif dengan lembaga pendidikan lain, bahkan bisa

Implementasi, (Bandung: PT. Remaja Rosdakarya, 2005), hlm. 31.

${ }^{3}$ Mujamil Qomar, Strategi Pendidikan Islam, (Jakarta: Erlangga, 2013), hlm. 74.

${ }^{4}$ Muhaimin dan Abdul Mujib, Pemikiran Pendidikan Islam, (Bandung: Triganda Karya, 1993), hlm. 286. 
hancur, terbelakang dan tidak diminati oleh masyarakat atau umat Islam. ${ }^{5}$

Dalam perkembangannya, lembaga pendidikan Islam mulai bertebaran dimana-mana hingga ke pelosok-pelosok desa. Perkembangan lembaga pendidikan Islam yang begitu pesat secara kuantitas menurut Baharuddin, sayangnya tidak dibarengi dengan masifnya kekuatan pengelolaan. Ini memunculkan kesan dari kalangan pengamat, termasuk Zuhri yang menilai bahwa perkembangan lembaga pendidikan Islam yang mencapai ribuan itu hanya masih terbatas pada jumlah diatas kertas. ${ }^{6}$

Dari sekian banyak lembaga pendidikan Islam saat ini, ada lembaga yang menarik perhatian penulis untuk melakukan penelitian di lembaga tersebut.Lembaga pendidikan tersebut adalah MA Nahdhlatul Ulama Gondang Sragen. Adapun keunikan-keunikan dari lembaga diatas sehingga penulis tertarik melaksanakan penelitian di lokasi tersebut adalah: Kurikulum yang digunakan di lembaga ini berbeda namun mampu menjadikan pendidikan yang bermutu. Kurikulum yang digunakan oleh MA NU Gondang Sragen adalah mengkolaborasikan kurikulum kementrian agama dengan kurikulum diknas, serta kurikulum lokal dari Ma'arif itu sendiri, lembaga ini mempunyai prestasi dan mutu yang sangat baik. Hal ini terbukti dengan adanya berbagai penghargaan yang diperoleh oleh lembaga tersebut dalam beberapa kegiatan MA

\footnotetext{
${ }^{5}$ Ibid, hlm.35

${ }^{6}$ Baharuddin, Pengembangan Lembaga Pendidikan Islam; Menuju Pengelolaan Profesional dan Kompetitif (Malang: UIN Maliki Press, 2012), hlm. 3. 
NU Gondang Sragen mampu mengantarkan peserta didiknya menjuarai perlombaan baik ditingkat regional maupun nasional, misalnya adalah juara II dalam lomba tahfidz al-qur'an dan juara I lomba pramuka tingkat kabupaten sragen dan sebagainya, lingkungan pondok pesantren yang asri kondusif dan sportif untuk pengembangan kepribadian Islam, siswa mendapatkan bimbingan secara maksimal dibidang materi pelajaran umum, diniyah dan mental spiritual.

Demikian beberapa alasan yang peneliti kemukakan sehingga lembaga tersebut peneliti anggap layak untuk diteliti dengan berdasar pada keunikan serta keunggulan yang dimiliki lembaga. Oleh karena itu, dalam upaya untuk terus mempertahankan dan meningkatkan mutu pendidikan di lembaga pendidikan Islam saat ini, penulis tertarik untuk melakukan penelitian Manajemen Strategik Lembaga Pendidikan Islam dalam Meningkatkan Mutu Pendidikan di Madrasah Aliyah Nahdlatul Ulama Gondang Sragen.

\section{B. TELAAH PUSTAKA}

\section{Manajemen Strategik Lembaga Pendidikan Islam}

Manajemen strategik lembaga pendidikan Islam adalah serangkaian keputusan dan tindakan manajerial lembaga pendidikan Islam yang meliputi kegiatan formulasi, implementasi dan evaluasi baik jangka pendek maupun jangka panjang secara berulang dan berkelanjutan dalam sebuah organisasi lembaga pendidikan Islam yang melibatkan sumber daya manusia dan non manusia dalam menggerakkannya dan memberikan kontrol secara strategis untuk mencapai tujuan yang diinginkan. 


\section{Proses Manajemen Strategik Lembaga Pendidikan}

\section{Islam}

a. Formulasi strategi (Strategi Formulation)

Prim Masrokan menjelaskan bahwa formulasi strategi mencerminkan keinginan dan tujuan organisasi yang sesungguhnya. Dalam hal ini, organisasi harus merumuskan visi, misi, nilai, mencermati lingkungan internal dan eksternal, serta membuat kesimpulan analisis faktor internal dan eksternal. ${ }^{7}$

b. Implementasi Strategi (Strategic Implementation)

Implementasi strategi menurut Hunger dan Wheelen adalah proses dimana manajemen mewujudkan strategi dan kebijakan dalam tindakan melalui pengembangan program, anggaran dan prosedur. Lebih lanjut dijelaskan bahwa proses implementasi strategi mungkin meliputi perubahan budaya secara menyeluruh, struktur dan atau sistem manajemen dari organisasi secara keseluruhan. ${ }^{8}$

c. Evaluasi Strategi (Pengawasan)

Evaluasi strategi adalah usaha-usaha untuk memonitor hasil-hasil dari perumusan (formulasi) dan penerapan (implementasi) strategi termasuk mengukur kinerja organisasi, serta mengambil langkah-langkah perbaikan jika diperlukan. ${ }^{9}$

\section{Mutu Pendidikan}

\footnotetext{
${ }^{7}$ Masrokan Mutohar, Manajemen Strategik dalam Meningkatkan Mutu Pendidikan..., 158.

${ }^{8}$ J. David Hunger \& Thomas L. Wheelen, Manajemen..., 17.

${ }^{9}$ Winardi Karshi Nisjar, Manajemen Strategikcet 1, (Bandung: Mandar Maju, 1997), hlm. 86.
} 
Menurut Jerome karakteristik sekolah bermutu ditandai oleh "lima pilar mutu". Secara terperinci prinsiprinsip atau lima pilar mutu terbsebut adalah sebagai berikut: ${ }^{10}$
a. Berfokus pada pelanggan (costomer)
b. Keterlibatan total
c. Pengukuran
d. Komitmen
e. Perbaikan berkelanjutan

4. Manajemen Strategik Lembaga pendidikan Islam dalam Meningkatkan Mutu Pendidikan

a. Formulasi Strategi dalam Meningkatkan Mutu Pendidikan

1) Formulasi Visi Dan Misi Sekolah

Perumusan visi dan misi dilakukan dahulu dengan mengasesmen lingkungan, yaitu apa yang sebenarnya yang menjadi kebutuhan mendasar lingkungan akan pendidikan yang dapat disediakan oleh sekolah. ${ }^{11}$ Asesmen lingkungan terdiri dari dua unsur yaitu lingkungan ekstemal dan internal. Asesmen lingkungan eksternal meliputi identifikasi dan evaluasi aspek-aspek sosial, budaya, politis, ekonomis, dan teknologi, serta kecenderangan yang mungkin berpengarah pada organisasi. Hasil asesmen lingkungan adalah sejumlah peluang

\footnotetext{
${ }^{10}$ Jerome S. Arcaro, Pendidikan Berbasis Mutu: Prinsip-prinsip Perumusan dan Tata Langkah Penerapan, (Yogyakarta: Pustaka Pelajar, 2005), hlm. 83.

${ }^{11}$ Sagala, Manajemen Strategik..., hlm.133 
(oportunities) yang haras dimanfaatkan oleh organisasi dan ancaman (threats) yang harus dicegah atau dihindari. Asesmen lingkungan internal terdiri dari penentu persepsi yang realistis atas segala kekuatan (strength) dan kelemahan (weaknesses) yang dimiliki organisasi.

Berikut skema proses formulasi strategi: ${ }^{12}$

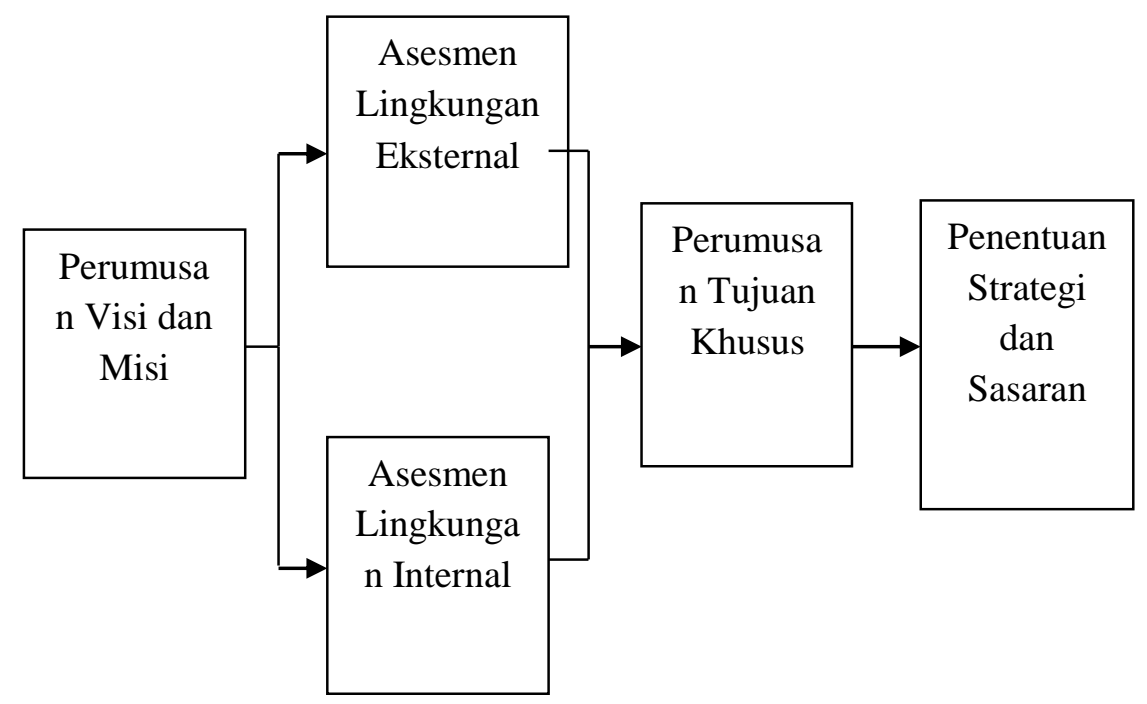

\section{Gambar 1. Proses Formulasi Strategi}

2) Perumusan Tujuan dan Target Sekolah

Akdon menegaskan bahwa target/sasaran organisasi sangat penting karena merupakan salah satu tonggak dari proses perumusan perencanaan strategik yang efektif yang mendukung setiap butir tujuan dan menyatakan tugas-tugas khusus yang

\footnotetext{
${ }^{12}$ Ibid., hlm.134.

Etik Kurniawati, Manajemen Strategik ...
} 
dirampungkan dalam jangka waktu pendek jika organisasi ingin sukses. ${ }^{13}$

3) Penentuan Strategi Organisasi Sekolah

Strategi organisasi adalah suatu pernyataan mengenai arah dan tindakan yang diinginkan oleh organisasi di waktu yang akan datang. Strategi organisasi tersebut mencakup kebijakan, program dan kegiatan-kegiatan manajemen untuk melaksanakan misinya. ${ }^{14}$

b. Implementasi Strategi dalam Meningkatkan Mutu Pendidikan

Prim Masrokan menegaskan bahwa implementasi strategi menggambarkan cara mencapai tujuan yang telah dirumuskan oleh organisasi. Kegiatan ini merupakan lanjutan dari formulasi strategi yang mempunyai beberapa prinsip kegiatan yaitu: (a) analisis pilihan strategik dan kunci keberhasilan, (b) penetapan tujuan, sasaran dan strategi (kebijakan, program dan kegiatan), (c) sistem pelaksanaan, pemantauan dan pengawasan yang haras dirumuskan dengan jelas berdasarkan hasil analisis yang telah dilaksanakan untuk mencapai tujuan secara efektif dan eflsien. ${ }^{15}$

Sebagai seorang kepala sekolah, ada dua tugas besar yang diemban dalam implementasi strategi yakni; tugas yang pertama adalah proses implementasi strategi ini benar-benar di-manage dengan sebaik mungkin agar

${ }^{13}$ Akdon, Akdon, Strategic Manajemen for Educational Management..., hlm. 146

${ }^{14}$ Ibid., hlm.150

${ }^{15}$ Masrokan Mutohar, Manajemen Strategik dalam Meningkatkan Mutu... hlm.158. 
apa yang telah diformulasikan sebelumnya bisa terlaksana dengan baik dan sesuai dengan harapan bersama. Tugas yang kedua adalah memanfaatkan semua sumber daya yang ada baik sumber daya manusia maupun sumber daya non manusia untuk mendukung terlaksananya semua formulasi strategi yang telah ditetapkan.

c. Evaluasi Strategi dalam Meningkatkan Mutu Pendidikan Evaluasi strategi dalam manajemen strategik adalah usaha- usaha untuk memonitor hasil-hasil dari perumusan (formulasi) dan penerapan (implementasi) strategi termasuk mengukur kinerja organisasi, serta mengambil langkah-langkah perbaikan jika diperlukan. ${ }^{16}$ Dengan adanya evaluasi strategi, organisasi pendidikan diharapkan mampu mengevaluasi diri untuk berbenah lebih baik kedepannya demi meingkatkan mutu pendidikan.

\section{Kerangka Berpikir}

Kerangka berpikir dalam penelitian ini adalah:

\footnotetext{
${ }^{16}$ Karshi Nisjar, Manajemen Strategik..., hlm.86. 


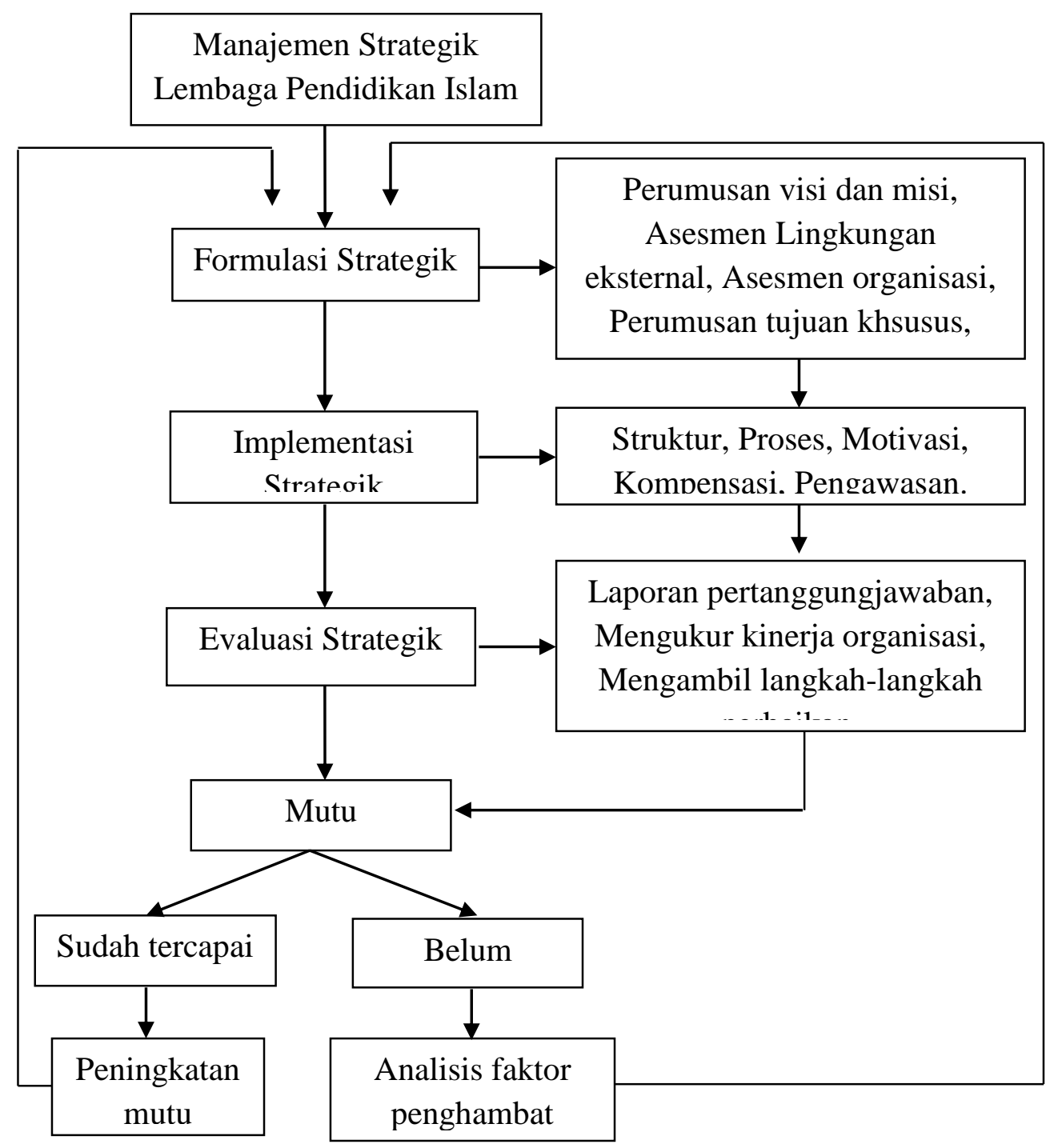

Gambar 2. Kerangka Berpikir Penelitian 


\section{PEMBAHASAN}

\section{Formulasi Strategi Lembaga Pendidikan Islam dalam} Meningkatkan Mutu Pendidikan

Asesmen lingkungan terdiri dari dua unsur yaitu lingkungan ekstemal dan internal. Hasil asesmen lingkungan adalah sejumlah peluang (oportunities) yang harus dimanfaatkan oleh organisasi dan ancaman (threats) yang harus dicegah atau dihindari. MA NU Gondang Sragen memanfaatkan prestasi siswa yang selalu meningkat, lulusan yang dihasilkan selalu diterima disekolah-sekolah favorit, SDM yang dimiliki sangat berkompeten, lingkungan yang kondusif, serta sarana prasarana yang memadai sebagai sebuah kekuatan untuk mewujudkan visi dan misi yang dirumuskan. Sedangkan animo masyarakat yang begitu besar dan persaingan yang ketat antar sekolah dijadikan sebagai sebuah peluang untuk terus maju demi mewujudkan visi dan misi.

Setelah visi dan misi dirumuskan, langkah selanjutnya yang ditempuh adalah menentukan tujuan dan target. Akdon menegaskan bahwa target/sasaran organisasi sangat penting karena merupakan salah satu tonggak dari proses perumusan perencanaan strategik yang efektif yang mendukung setiap butir tujuan dan menyatakan tugas-tugas khusus yang dirampungkan dalam jangka waktu pendek jika organisasi ingin sukses. ${ }^{17}$

Setelah tujuan dan target dirumuskan maka langkah selanjutnya adalah menentukan strategi untuk mewujudkan

\footnotetext{
${ }^{17}$ Akdon, Akdon, Strategic Manajemen for Educational Management..., hlm. 146 
visi, misi tujuan dan target yang telah ditetapkan. Dalam merumuskan strategi, MA NU Gondang memanfaatkan forum rapat kerja untuk merumuskan strategi terbaik. Sesuai dengan hasil penelitian yang diperoleh, ada lima strategi yang dirumuskan oleh MA NU Gondang Sragen. Strategistrategi tersebut adalah pengembangan kurikulum, peningkatan kualitas kinerja dan kesejahteraan SDM, membangun citra sekolah dan peningkatan prestasi akademik siswa, menciptakan lingkungan sekolah yang harmonis, pengadaan dan standarisasi sarana-prasarana.

Strategi yang dilakukan untuk meningkatkan mutu pendidikan melalui kurikulum adalah dengan melakukan pengembangan kurikulum. Pengembangan kurikulum menjadi fokus pertama dalam meningkatkan mutu pendidikan.

Sementara itu, strategi yang kedua adalah meningkatkan mutu pendidikan melalui peningkatan SDM, inti dari pemberdayaan itu sendiri meliputi tiga hal yaitu pengembangan, memperkuat potensi/daya, terciptanya kemandirian. Sementara itu, untuk peningkatan mutu melalui peningkatan sumber daya alam maka akan berfokus pada peningkatan sarana dan prasarana. Manajemen sarana dan prasarana pendidikan merupakan hal yang sangat menunjang atas tercapainya suatu tujuan pendidikan.

Langkah selanjutnya yang ditempuh oleh MA NU Gondang adalah peningkatan prestasi akademik siswa. Peningkatan prestasi akademik siswa menjadi penting dikarenakan prestasi siswa merupakan salah satu faktor 
mutu pendidikan. Untuk mewujudkan hal tersebut maka prestasi belajar siswa baik akademik maupun non akademik dituntut untuk benar-benar ditingkatkan.

Strategi terakhir agar mutu pendidikan dapat ditingkatkan adalah membangun citra lembaga. Salah satu cara untuk membangun citra lembaga yang ditempuh oleh MA NU Gondang ini adalah menjalin hubungan sosial baik dengan sesama lembaga pendidikan maupun dengan masyarakat.

Hubungan sekolah dengan masyarakat adalah suatu kegiatan komunikasi yang lebih terarah antara sekolah dan masyarakat melalui langkah-langkah: saling mengenal, saling memahami, saling mengasihi, saling menolong, dan saling menanggung, sehingga terwujud kerja sama yang baik dan saling menguntungkan kepada pihak-pihak yang terkait, dengan tujuan utamanya yaitu untuk meningkatkan mutu pendidikan.

Sesuai dengan teori Prim Masrokan menjelaskan bahwa formulasi strategi mencerminkan keinginan dan tujuan organisasi yang sesungguhnya. Dalam hal ini, organisasi harus merumuskan visi, misi, nilai, mencermati lingkungan internal dan eksternal, serta membuat kesimpulan analisis faktor internal dan eksternal. ${ }^{18}$

\section{Implementasi Strategi Lembaga Pendidikan Islam dalam Meningkatkan Mutu Pendidikan}

\footnotetext{
${ }^{18}$ Prim Masrokan Mutohar, Manajemen Strategik dalam Meningkatkan Mutu Pendidikan; Konsep dan Implementasinya di Lembaga Pendidikan Islam, Jumal, EPISTEME, Vol 3, No 2, (Tulungagung, PPs STAIN Tulungagung, 2008), hlm. 158
} 
Implementasi strategi dalam konteks manajemen strategik adalah proses menjabarkan strategi-strategi yang telah dirumuskan kedalam bentuk tindakan-tindakan nyata. Tindakan-tindakan tersebut kemudian di manage dengan baik agar strategi-strategi tersebut terwujud.

Dalam proses implementasi strategi, seorang kepala sekolah harus memanfaatkan segala sumber daya yang ada baik sumber daya manusia maupun non manusia untuk mewujudkan strategi tersebut. Menempatkan sumber daya manusia sesuai dengan kemampuannya dan menggunakan sumber daya non manusia dengan maksimal akan mampu mewujudkan strategi tersebut. Sebaliknya, jika tidak dikelolah dengan baik maka strategi tersebut tidak akan terwujud.

Dalam mengimplementasikan strategi yang telah dirumuskan, MA NU Gondang merumuskan beberapa kegiatan-kegiatan. Teknis pelaksanaan kegiatan-kegiatan tersebut diserahkan kepada koordinator masing-masing. dalam pelaksanaannya, kepala sekolah menggunakan sistem control dengan menjalin komunikasi intensif dengan koordinator kegiatan. Sistem lain yang diterapkan oleh kepala sekolah MA NU Gondang Sragen adalah dengan melakukan pengamatan, pengawasan, dan pengecekan secara berkala. Sistem control yang digunakan oleh kepala sekolah MA NU Gondang Sragen bervariasi. Kadang dengan langsung terjun ke lapangan, kadang menggunakan apel pagi dan kadang hanya menemui wakil-wakil kepala sekolah. 
Penyerahan teknis pelaksanaan kepada koorditaror kegiatan memang tidaklah salah. Namun, sebagai seorang pemimpin, alangkah lebih baik untuk mengetahui teknis pelaksanaan kegiatan tersebut. Hal ini dimaksudkan agar mempermudah sistem pengontrolan, pengawasan maupun pemantauan.

Oleh karena itu, sebagai kepala sekolah, selain menempatkan semberdaya manusia sesuai dengan kemampuannya dan memanfaatkan sumber daya non manusia dengan semaksimal mungkin, kepala sekolah juga harus melakukan pengawasan sebaik mungkin agar implementasi strategi berjalan sesuai rencana.

\section{Evaluasi Strategi Lembaga Pendidikan Islam dalam} Meningkatkan Mutu Pendidikan

Evaluasi strategi yang dilakukan oleh MA NU Gondang Sragen adalah dengan mengadakan rapat rutin internal bidang dan rapat menyeluruh. Dua jenis rapat ini dimanfaatkan oleh MA NU Gondang Sragen untuk melakukan evaluasi strategi- strategi yang telah diimplementasikan. Lembaga akan mengambil langkahlangkah perbaikan kedepan agar strategi yang dirumuskan nantinya berjalan dengan lancar.

Akdon menjelaskan bahwa secara garis besar ada dua jenis evaluasi, yaitu: a. evaluasi formatif meliputi evaluasi yang dilakukan sebelum program berjalan, atau sedang dalam pelaksanaan, atau setelah program selesai dan dapat diteliti hasil dan dampaknya; b. evaluasi sumatif, yakni evaluasi yang dilakukan untuk beberapa 
periode/tahun sehingga memerlukan pengumpulan data time series untuk beberapa tahun yang dievaluasi. ${ }^{19}$

Menurut analisis peneliti, dua jenis evaluasi yang dijabarkan oleh Akdon telah diterapkan oleh kedua lembaga yang diteliti baik evaluasi formatif maupun evaluasi sumatif. Oleh karena itu, hasil evaluasi strategi merupakan acuan dalam upaya peningkatan kualitas pendidikan dan rencana pengembangan sekolah, dan sekaligus menjadi bahan masukan untuk usaha pembinaan dan pengembangan kinerja warga sekolah dalam rangka menerapkan visi, misi, dan peningkatan status jenjang akreditasi sekolah, termasuk dimanfaatkan sebagai tolok ukur untuk persaingan kualitas sekolah pada tingkat intemasional, regional, nasional, propinsi, maupun tingkat kabupaten/kota.

\section{KESIMPULAN}

Berdasarkan hasil penelitian dan pembahasan pada bab sebelumnya, maka dapat peneliti simpulkan sebagai berikut:

1. Formulasi strategi di MA NU Gondang Sragen dilakukan dengan terlebih dahulu merumuskan visi dan misi dengan mempertimbangkan lingkungan internal dan ekstemal, dilanjutkan dengan penetapan tujuan dan target dan dilanjutkan dengan penentuan strategi.

2. Implementasi strategi di MA NU Gondang Sragen dilakukan dengan menjabarkan strategi- strategi yang telah

\footnotetext{
${ }^{19}$ Akdon, Strategic Manajemen for Educational Management; Manajemen Strategik untukManajemen Pendididkan, (Bandung, ALFABETA, 2006), hlm. 176-177 
dirumuskan dalam bentuk kegiatan-kegiatan. Teknis pelaksanaannya diserahkan kepada koordinator kegiatan dengan tetap berkoordinasi dengan kepala sekolah. Sistem pengawasan dilakukan dengan menerapkan komunikasi intensif serta pengontrolan rutin kepada koordinator kegiatan.

3. Evaluasi strategi di MA NU Gondang Sragen dilakukan melaui rapat informal maupun formal. Rapat formal dilakukan secara rutin baik di tingkat internal bidang maupun secara menyeluruh.

\section{E. DAFTAR PUSTAKA}

Akdon. 2006. Strategic Manajemen for Educational Management. Bandung: ALFABETA

Alma, Buchori dkk. 2009. Menejemen Corporate Strategi pemasaran Jasa pendidikan.Bandung: Alfabeta

Anwar. 1999. Metode Penelitian. Yogyakarta: Pustaka Pelajar Ary Irawan.2011. Implementasi Manajemen Strategik dalam Mengelola Sekolah Unggul.Malang: PPs UM

Baharuddin \& Umiarso. 2012. Kepemimpinan Pendidikan Islam. Jogjakarta: Ar-Ruzz Media

Dakir, 2004. Perencanaan dan Pengembangan Kurikulum, Cet. Ke-1, Jakarta: Rineka Cipta

Departemen Agama. 2006. AI-Qur'an dan Terjemahan. Kudus: PT. Menara Kudus

Departemen Pendidikan dan Kebudayaan.2001. Kamus Besar Bahasa Indonesia.Jakarta: Balai Pustaka

Himpunan Peraturan Perundang-Undangan Pengelolaan dan Penyelenggaraan Pendidikan. 2010. Bandung : Fokusmedia

Karshi Nisjar, Winardi. 1997. Manajemen Strategik,cet 1. Bandung: Mandar Maju

Masrokan Mutohar, Prim. 2014. Manajemen Mutu Sekolah;

Strategi Peningkatan Mutu dan Daya Saing Lembaga

Pendidikan Islam, Cet. II. Jogjakarta: Ar-Ruzz Media

Muhaimin dan Mujib, Abdul. 1993. Pemikiran Pendidikan 
Islam. Bandung: Triganda Karya

Mulyasa, E.. 2005. Manajemen Berbasis Sekolah, Konsep, Strategi, dan Implementasi. Bandung: PT. Remaja Rosdakarya

Mulyono, 2008. Manajemen Administrasi dan Organisasi Pendidikan,

Jogjakarta, Ar-Ruzz Media

Nanang Fattah, 2004, Landasan Manajemen Pendidikan, Bandung: PT. Remaja Rosdakarya, , 2013. Sistem Penjaminan Mutu Pendidikan,

Bandung: Remaja Rosdakarya

Pearce, Robinson. 1997. Manajemen Strategik Formulasi, Implementasi dan Pengendalian Jilid 1. Jakarta: Binarupa Aksara

Qomar, Mujamil. 2013. Strategi Pendidikan Islam. Jakarta: Erlangga

Sagala, Syaiful. 2013. Manajemen Strategik dalam Peningkatan Mutu Pendidikan.Bandung: Alfabeta

Standar Nasional Pendidikan.PP. RI.No. 19 Tahun 2005. Jakarta: Redaksi Sinar Grafika

Usman, Husaini. 2008. Manajemen Teori Praktik \& Riset Pendidikan, edisi kedua.Jakarta: Bumi Aksara

Winardi Karshi Nisjar, 1997. Manajemen Strategik, cet 1, Bandung: Mandar Maju 